\title{
CONSTITUCIÓN CONSERVADORA CHILENA DE 1833 Y LA VISIÓN CRÍTICA DE ALBERDI
}

FRANCISCO ZÚNIIGA URBINA 
SUMARIO

PROLEGÓMENOS. I. CONSTITUCIÓN CONSERVADORA DE 1833: LA REPÚBLICA AUTOCRÁTICA Y OLIGÁRQUICA. II. VISIÓN CRÍTICA DE ALBERDI. III. CONCLUSIONES. 


\title{
CONSTITUCIÓN CONSERVADORA CHILENA DE 1833 Y LA VISIÓN CRÍTICA DE ALBERDI ${ }^{1}$
}

\author{
POR \\ FRANCISCO ZÚNIIGA URBINA \\ Profesor de Derecho Constitucional \\ Universidad de Chile y Universidad Diego Portales
}

\section{PROLEGÓMENOS}

En su monumental «Historia de América» el historiador argentino Ricardo Levene nos recuerda que la Constitución de 1853 es «representativa, republicana y federal» y en ella la visión de Juan Bautista Alberdi se inspira en ideas muy precisas: «....una Constitución no es un cuerpo de doctrinas o teoría reflejo de la ilustración de un legislador sino la expresión auténtica de la historia de un pueblo, de sus costumbres, de su modo predominante de ser y sentir». El «Padre de la Constitución Argentina» (Linares Quintana) fue hostil a las abstracciones desvinculadas de la historia y abogó por una Constitución rígida que le diera estabilidad al régimen político ${ }^{2}$. El constitucionalismo de Alberdi, fundido en esa caldera de ideas que fue la "generación del 37», se inscribe en lo que podemos

${ }^{1}$ Ponencia a Congreso Homenaje a Juan Bautista Alberdi y fundación del Instituto Latinoamericano de Derecho Público, 15 a 17 de octubre de 2008, Asunción, Paraguay.

2 LEVENE, Ricardo, Historia de América, Buenos Aires, W. M. Jackson Inc. Editores, 1949, Vol. VI, Cap. I: «La Argentina hasta la Constitución de 1853», pp. 9-218, y también Vol. X. Consultar la monumental obra de Linares Quintana, Segundo, Tratado de la Ciencia del Derecho Constitucional Argentino y Comparado, Buenos Aires, Editorial Plus Ultra, 2. ${ }^{\text {e ed., }}$ 1977-1987, en especial Vol. 1, pp. 426-432 y Vol. 7, pp. 146-149. 
denominar «liberalismo temperado» propio del mundo post Santa Alianza con una temprana influencia de Escuela Histórica de F.C. v. Savigny, marcado por su preocupación por el «mejoramiento de la raza», europeización de las costumbres, inmigración libre, introducción de la técnica, aumento de la producción, libertad de comercio y difusión de la enseñanza.

Debemos destacar además la originalidad y vastedad de la obra iuspublicística de Alberdi reflejada en sus obras completas y escritos póstumos, la utilización de la comparación diacrónica (historia) y sincrónica (comparatismo), a la que se suma erudición y solidez dogmática. Nos proponemos en este breve trabajo abordar la visión crítica de Juan Bautista Alberdi exiliado de la dictadura de Rosas en Chile durante un largo periodo de tiempo (1844-1855) formando parte de un tercer grupo de emigrados junto a Gutiérrez, Echeverría, Belgrano, entre otros, principalmente plasmada en sus «Bases y puntos de partida para la organización política de la República Argentina» y en su correspondencia desde Valparaíso, y desde los distintos lugares de su peregrinar. Las «Bases...» reflejan como ninguna otra de sus obras, las características anotadas de la obra jurídica alberdiana, y un especial cuño ideológico jurídico: la influencia del constitucionalismo norteamericano y francés, e incluso su método expositivo guarda relación con los "Comentarios» de J. Story, tres décadas más tarde traducido a nuestra lengua con anotaciones por Nicolás Calvo. En cuanto al ejercicio dogmático de Alberdi sobresalen algunas señaladas ideas: definición de Constitución e importancia de su estructura normativa y garantías, subrayando la estabilidad de las reglas constitucionales y potencialidades de la interpretación.

En Chile Alberdi obtiene la reválida del título de abogado en la Universidad de Chile presentando la memoria «Congreso General Americano» en 1844 en que brega por la unión aduanera de nuestra América, trabaja en la Intendencia en Concepción y como abogado en Santiago, para afincarse en Valparaíso más tarde, desarrollando un labor de publicista, periodista y empresario a través del Mercurio o fundando el periódico «El Comercio» (1847-1849) y el «Club Constitucional» presidido por Gregorio Gómez para apoyar los planes constitucionales del general Urquiza; siendo nombrado por éste Encargado de Negocios de la Confederación en Chile en 1852 y más tarde en 1855 en Europa iniciando un largo periplo diplomático.

La visión crítica de Alberdi esta marcada por la agudeza histórica que atempera su liberalismo (y también su republicanismo), de lo que es elocuente la síntesis de su aproximación constitucional, y de su disputa con Sarmiento derivada de la Constitución de 1853 y su lejanía de la Constitución norteamericana, recogida en sus "Cartas quillotanas». Advierte, a pesar de su lectura de la Constitución conservadora de 1833 lo siguiente: «Ninguna de las constituciones de 
Sud-América merece ser tomada por modelo de imitación...» (p. 17), más aún realizando una lectura comparatista de las constituciones del continente (Chile, Perú, Colombia, México, Uruguay y Paraguay, entre otras ) sentencia que tal derecho constitucional se opone a los intereses de su "progreso material e industrial», habiendo superado los países la brecha de la independencia.

Tal agudeza histórica le hace observar en la Constitución conservadora o "pelucona» de 1833 un precipitado normativo fundamental de los intereses de las clases dominantes herederas del viejo orden indiano colonial, frente a un raquítico liberalismo. Al mismo tiempo la centralidad presidencial en la Constitución conservadora es engarzada con la necesidad de imponer un orden para la formación del Estado nacional. Alberdi observa en América del Sur una posición falsa: tienen repúblicas como fórmula de organización, pero estas no son una «verdad práctica en su suelo», por lo que deben mejorar los gobernados para mejorar su Gobierno. Sin embargo, sobre Chile llama la atención acerca del grado de republicanismo, ya que posee una «...Constitución monárquica en el fondo y republicana en la forma», uniendo el pasado con la «vida moderna».

Contrasta la agudeza histórica de la crítica, con el rol «demiúrgico» asignado por Alberdi a Juan Egaña y su hijo Mariano Egaña, en la gestación de la Constitución "pelucona» de 1833, que dista en parte de la realidad o es una notoria exageración.

En la perspectiva de la formación del Estado nación la Constitución de 1833 consolida un proceso centralizador y autoritario iniciado con la Constitución liberal o "pipiola» de 1828, pasando parte importante de su cuerpo de normas a la Constitución conservadora, por lo que interpreta la realidad histórico y cultural, aunque tropieza con los mayorazgos y la Iglesia (Heise). El peluconismo, es un abigarrado grupo o clase social formada por la «falange de los mayorazgos» (Vicuña Mackenna) u oligarquía mercantil, denominada impropiamente por las corrientes histórico-conservadoras «aristocracia» o con rasgos míticos «aristocracia castellano-vasca», cuyo capital había sido acumulado entre 1570 y 1812 durante el Estado "de señorío», clase dirigente carente de verdadera cultura republicana y menos democrática, más bien su ethos es monárquico. En ese contexto el «discurso de poder» que uniera a la clase dirigente y proyectara las bases del Estado, fue una obra práctica de la «dictadura» de D. Portales P. con la ayuda de «publicistas» como Manuel Gandarillas, Manuel Rengifo, Mariano Egaña, Andrés Bello, entre otros, y que se impone por la fuerza con la derrota liberal en Lircay en $1830^{3}$.

${ }^{3}$ Consultar a Heise González, Julio, 150 años de Evolución Institucional, Santiago, Editorial Andrés Bello, 6. ${ }^{\mathrm{a}}$ ed., 1989, pp. 34-37. También consultar a Salazar, Gabriel y Pinto, Julio, His- 
La Constitución conservadora permitió imponer un orden político autocrático de formas republicanas, puesto al servicio de un "práctico libremercadismo exterior», y con ello el "peso de la noche» o dominación social de las clases tradicionales, de un «orden señorial y jerárquico», más todo el peso de la Iglesia.

\section{CONSTITUCIÓN CONSERVADORA DE 1833: LA REPÚBLICA AUTOCRÁTICA Y OLIGÁRQUICA}

La irrupción conservadora va de la mano con un Congreso de Plenipotenciarios que declara nulos los actos del Congreso de mayoría liberal y concede facultades extraordinarias, mecanismo usual de Gobierno durante buena parte del siglo XIX.

Mediante una ley de 1 de octubre de 1831 se decidió reformar la Constitución de 1828 invocando el artículo 133 del texto constitucional. En este artículo se establecía una Gran Convención para resolver sí se debía o no reformar el texto constitucional, sin embargo, se fijaba como fecha para la celebración de sus reuniones el año 1836, no el 1831. El objeto de esta Convención según el artículo 133 era reflexionar sobre la necesidad o no de la reforma ${ }^{4}$. Estamos en presencia en la génesis de la Constitución conservadora de una «infracción» a la Constitución liberal y su plazo de espera hasta 1836 para la reforma.

La asamblea calificada por los conservadores como Gran Convención se formó con dieciséis diputados del Congreso y veinte ciudadanos de conocida probidad e ilustración. A estos ciudadanos se les exigió reunir los requisitos para ser diputados según las normas de la propia Constitución de 1828.

La Gran Convención formó el 21 de octubre una comisión integrada por Manuel Gandarillas, Agustín Vial, Fernando Antonio Elizalde, a la que se encargó emitir un dictamen sobre si debía o no reformarse el texto constitucional. Ésta opinó que debía reformarse y sometido a votación su dictamen el día 24 de octubre fue aprobada la idea de reformar la Constitución por una unanimidad de los miembros presentes.

toria Contemporánea de Chile. Estado, Legitimidad y Ciudadanía, Santiago, Ediciones LOM, 2001, pp. 31-35. También consultar a Jocelyn-Holt L., Alfredo, El peso de la noche. Nuestra frá-

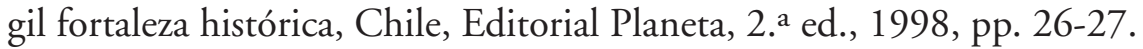

${ }^{4}$ PALMA GONZÁLEZ, Eric Eduardo, Historia del Derecho Chileno (1808-1924), Santiago, Facultad de Derecho, Universidad de Chile, 2004. 
Se acordó entonces el 25 de octubre de 1831 nombrar una comisión que presentara a la asamblea un proyecto de Constitución y se designó a Agustín Vial, Santiago Echeverz, Manuel Gandarillas, Mariano Egaña, Gabriel Tocornal, Fernando Antonio Elizalde y Juan Francisco Meneses. En la ocasión se dejó establecido que la tarea de la Comisión sólo era proponer modificaciones sin alterar el fondo del código en parte sustancial 5 .

La Comisión de reforma concluyó su trabajo en los primeros días del mes de abril de 1832 y a fines de mayo salió el proyecto de la imprenta. Con fecha 17 de mayo el publicista Egaña presentó un proyecto de reforma preparado por él y por Agustín Vial, y se acordó que se debatiría conjuntamente con el de la Comisión.

La dilación del trabajo de la Comisión de Constitución implicó críticas tanto por parte de la prensa oficialista como opositora y dio pie para que se recordada que la Gran Convención sólo había sido autorizada para reformar y adicionar el Código Político, y no para darnos uno nuevo, que no necesitamos, que no quieren los pueblos y que sería mas peligroso que el que nos rige. Límite la Comisión sus proyectos a la órbita de sus atribuciones y ahorrará tiempo y reconvenciones a que no puede contestar.

Cabe recordar en este sentido las expresiones del Presidente de la República cuando inauguró las sesiones de la Gran Convención: «...vuestra misión no es hacer otro pacto social, sino proveer medios que faciliten la ejecución del que existe y afiancen su permanencia...» (SCLCH, p. 27)

El tema no era menor puesto que existía plena conciencia en la época de que una nueva constitución sólo podía emanar de un verdadero Poder Constituyente.

A fines de octubre de 1832 se iniciaron los debates en el seno de la Convención, que recordemos, es una instancia diferente del Congreso.

Resulta ilustrativa del estado espiritual del momento la justificación que se da por «El Araucano» del hecho de que no se discuta el proyecto en el seno del Congreso. En primer término se señaló que la Constitución le otorgó sólo a la Gran Convención la facultad de reformar el texto; en segundo lugar se sostuvo que las discusiones resultarían perjudiciales: el celo de cada uno por satisfacer sus dudas,

5 Consultar sobre la historia fidedigna de la Constitución conservadora la recopilación de materiales de Letelier M., Valentín conocida como Sesiones de los Cuerpos Legislativos de la República de Chile de 1811 a 1845, abreviadas como SCLCH, y la invaluable recopilación de actas, sesiones, discursos, proyectos y artículos de diarios bajo el título «La Gran Convención de 1831-1833» preparada con los antecedentes de las «Sesiones» Tomo XXI por el mismo Letelier, publicada por Imprenta Cervantes, Santiago, 1906. 
para averiguar la verdad, para elegir lo mejor, es un principio fecundo de dilaciones y entorpecimientos. Podrá responderse que es el medio mejor para conseguir el acierto: pero no podrá negarse que en la divergencia de las opiniones y en las ideas mas o menos exaltadas de una reunión tan numerosa hay obstáculos invencibles, o al menos dificultades muy trabajosas que estorban el que suceda una conformidad de opiniones con la prontitud que exige la situación del país. Podrá conseguirse la aceptación de la reforma a costa de una gran demora y esto es un mal. ¿Y si el resultado es la repulsa? Habremos perdido todo el trabajo, y tendremos que permanecer mas tiempo en la situación vacilante en que nos ha colocado esos defectos de la Constitución que ocasionaron los males de que solo hemos podido librarnos, separándonos de sus disposiciones, mas acomodadas para favorecer el desorden que para asegurar la tranquilidad de los pueblos (SCLCH, p. 3). Esta idea se va a repetir en «El Araucano» a propósito del retardo en que se incurría por la comisión que estudiaba el proyecto de Constitución.

Observa Palma González: «Se aprecia nítidamente que se desconfía del debate público, y que el propósito de la reunión es imponer al país un modelo constitucional sobre el cual existe algún grado de consenso en el seno del conservadurismo, restando sólo buscar su legitimación para lo cual sirve aparentar respeto por las fórmulas constitucionales».

Agrega Palma González: «Públicamente se justifica la reforma y adición del texto a partir de la necesidad de amparar el orden público. Así queda de manifiesto en el juramento que debieron prestar los miembros de la Convención: Juro por Dios Nuestro Señor examinar la Constitución Política de Chile,... y si hallare conveniente su reforma o modificación, concurrir a hacerla, según el dictamen de mi conciencia, en los términos más oportunos para asegurar la paz y tranquilidad del pueblo chileno. Si así no lo hiciere Dios y la Patria me lo demanden».

De este modo, se dispuso asimismo en la ley de 1 de octubre que concluidos los trabajos de reforma debía el Presidente de la República convocar al Congreso para pasarle el Código presentado por la Convención. La tarea del Congreso quedó sólo limitada a jurar el Código reformado a nombre de la Nación. Jurado el Código por el Congreso, llamará al Poder Ejecutivo para que jure también observar y hacer cumplir como ley fundamental de la República de Chile, el Código reformado por la Convención. Quedando obligado a publicarlo como Constitución del Estado.

De lo expuesto podemos dar cuenta del contexto histórico e ideológico de la Constitución conservadora o "pelucona» de 1833 y la cuestión menor acerca de su «autoría», menor por que es una Constitución que releja un nuevo orden impuesto después de Lircay. 
Una segunda materia de interés ligada a la visión critica de Alberdi acerca de la Constitución conservadora de 1833 es su estatuto del poder autocrático y oligárquico, y que aquilata en una centralidad presidencial que nuestro autor anota con agudeza y estima necesaria.

En cuanto a la Constitución pelucona de 1833 un bosquejo general de su estatuto del poder político que nos permite designarla como un estatuto propio de una «república autocrática», pudiendo resumirse del modo siguiente:

1. «El Poder Ejecutivo». La Constitución de 1833 no se ajustó estrictamente al régimen presidencial; pero tampoco siguió el régimen parlamentario de Inglaterra. Se adoptaron disposiciones de ambos regímenes predominando el presidencial. Del régimen parlamentario sólo contiene la facultad del Congreso para autorizar cada 18 meses el cobro de las contribuciones, la aprobación anual de los presupuestos y la autorización anual de las fuerzas de mar y tierra (leyes periódicas). Pero la Constitución de 1833 se inclinaba francamente al régimen presidencial ${ }^{6}$.

En la práctica, los constituyentes de 1833 no le señalaron límites a la autoridad presidencial. Se convencieron que legitimando constitucionalmente la dictadura, los inconvenientes de ésta serían reducidos a su mínimo (Heise), como ocurrió con el derecho de excepción y facultades extraordinarias, que permitían suspender la «vigencia de la Constitución».

La concentración de poderes o atribuciones del Presidente de la República, reforzadas por la ley electoral, hicieron del Presidente de Chile, el «gran elector» durante 60 años, hasta la contra-revolución que depuso al presidente Balmaceda. Los otros poderes, el Congreso y la Municipalidad, que dentro de la Constitución aparecían como teóricamente independientes, fueron a lo largo de 60 años hechuras del gobierno. El giro se produce con el declive del rol presidencial de «gran elector» y la aprobación del proyecto conservador de la «comuna autónoma».

El sufragio limitado y controlado por el Poder Ejecutivo, el veto absoluto que se le concedía en la formación de las leyes, la ausencia de responsabilidad efectiva en el Jefe del Estado, las facultades extraordinarias, la organización del Consejo del Estado, la preponderancia de la Cámara de Senadores con su Comisión Conservadora de propio nombramiento manifiestan claramente el espíritu autoritario y oligárquico de la Constitución.

${ }^{6}$ HEISE GONZÁLEZ, Julio, Historia Constitucional de Chile, Santiago, Editorial Jurídica de Chile, 2. ${ }^{\mathrm{a}}$ ed., 1954. 
2. «El Poder Legislativo». Teóricamente el Congreso bicameral disponía de las mismas facultades que el Parlamento inglés. Tales fueron la de dictar anualmente los presupuestos y la ley que fija las fuerzas de mar y tierra y cada 18 meses, la que autoriza el cobro de las contribuciones.

Los ministros eran responsables ante las Cámaras y tenían derecho a asistir a sus debates.

La Constitución de 1833 contiene, pues, los gérmenes que permitirán más adelante la anulación de la formidable autoridad presidencial porque las armas constitucionales que se entregaban al Congreso bastaban para hacer de éste el árbitro de los destinos del país (Heise).

El «parlamentarismo» estaba en germen en la Constitución de 1833, Egaña, que fue el autor del proyecto, conocía el mecanismo parlamentario inglés (en el proyecto de Egaña ni siquiera se omite el derecho del ejecutivo para disolver el Congreso). De suerte que Mariano Egaña «comprendió claramente el alcance práctico que para el futuro tendrían las facultades con que armó al Congreso» (Heise).

En este sentido, la Constitución de 1833 fue más liberal que la de 1828 en lo referente a fijar aquellas atribuciones del Congreso que han dado origen al sistema parlamentario en todos los países. La Constitución de 1828 no contempla las leyes constitucionales relativas a los presupuestos y contribuciones.

Algunos historiadores están de acuerdo en estimar como uno de los méritos más sobresalientes del estatuto de 1833 el haber sembrado el germen del parlamentarismo que creciendo con el tiempo permitiría a las instituciones desarrollarse paulatinamente a medida que se organizaran los partidos, las fuerzas sociales y la opinión pública.

El Senado estaba constituido por 20 miembros que duraban 9 años en sus funciones y eran elegidos en votación indirecta en todo el territorio de la República. Representaban al país entero, eran en rigor «senadores de la República». El Senado llegó a formar un cuerpo esencialmente oligárquico, que en la práctica era elegido por el propio Presidente de la República erigido en "gran elector». Se renovaba por terceras partes y sus miembros podían ser reelegidos indefinidamente.

Los Diputados duraban 3 años en sus funciones. Como no existían las incompatibilidades, el ejecutivo podía otorgar empleos a los congresales o llevar al congreso a los empleados públicos.

En suma: la obra de los constituyentes de Portales, Egaña incluido, adecuada a las necesidades del país, tales como éstas se presentaban en 1830, no fue, sin embargo, «un obstáculo para que, con el tiempo, organizados los partidos y madura la opinión pública, el gobierno sin trastornos, llegara al más amplio liberalismo» (Heise). 
3. «El absolutismo presidencial y la aristocracia». Los principios moderadores del absolutismo presidencial yacen en la Constitución como gérmenes. En un comienzo el «Poder Ejecutivo» lo absorbe todo, el Presidente de la República es como se afirma cargando las tintas un «monarca temporal, absoluto e irresponsable».

Sin embargo, el absolutismo presidencial en Chile no debemos imaginarlo como un «despotismo sudamericano» (Heise). Desde luego, hay una diferencia y ella es que en Chile este absolutismo es constitucional, está consagrado en la ley. Los que lo ejercen no serán aventureros de la política, hombres obscuros, o productos del militarismo, como ocurre con los dictadores de otros países latinoamericanos.

Además, desde un comienzo nuestro absolutismo presidencial se encontrará con una fuerza moderadora extraconstitucional: la aristocracia que se manifestará en la clase política parlamentaria, que los historiadores conservadores denominan "fronda aristocrática» (Edwards). Observa Heise que la «alta burguesía» tomó dos decisiones básicas al organizar el Estado: «legitimar la dictadura portaliana, traducirla en instituciones legales», lo que es obra de Egaña y Gandarillas; y frenar el autoritarismo presidencial, que fueron el aporte de Egaña a través de las leyes periódicas y otros preceptos, transformando a las cámaras o cuerpos legislativos en la salvaguarda frente a este autoritarismo, todo bajo el influjo doctrinario anglo-francés ${ }^{7}$.

En este contexto, las leyes periódicas, censuras, interpelaciones, entre otros mecanismos morigeradores del absolutismo presidenciales van a consolidar tempranamente, y devienen en frecuentes herramientas del Congreso frente al Gobierno a partir de 1891.

Por consiguiente, las reformas constitucionales a la Constitución de 1833 a partir del Constituyente de 1871, no tienen por objetivo mudar de régimen político (presidencial a parlamentario), aunque sí morigerar los componentes autocráticos y oligárquicos de la Carta pelucona.

Desde esta suerte, la historia política de Chile en el siglo pasado, se reduce simplemente al avance sucesivo del poder moderador del absolutismo presidencial (la aristocracia) que se realiza dentro y fuera del Parlamento hasta que llega un momento en que nuestros presidentes deben contar con ese poder moderador y respetarlo (Heise). La crisis, «revolución» o «contrarrevolución» de

7 HEISE GONZÁLEZ, Julio, Historia de Chile. El Período Parlamentario 1861-1925, Tomo I: Fundamentos Histórico-culturales del Parlamentarismo Chileno, Santiago, Editorial Andrés Bello, 1974, pp. 17, 22-23, 28-29. 
1891, que pone fin al Gobierno del presidente J.M. Balmaceda es en un sentido al menos la expresión dramática y cruenta del triunfo de la oligarquía sobre el absolutismo presidencial.

\section{VISIÓN CRÍTICA DE ALBERDI}

Utilizando la obra «Estadística Bibliográfica de la Literatura Chilena» de Ramón Briseño, podemos extraer una ingente producción publicística de Juan Bautista Alberdi en Chile, sobresaliendo según hemos dicho las «Bases....» escritas, en el lapso de un par de semanas al calor del momento constituyente allende los Andes con pretensiones de influir decisivamente, en Valparaíso en 1852 y publicadas por la Imprenta El Mercurio, Valparaíso, reeditada el mismo año, y su correspondencia ${ }^{8}$.

${ }^{8}$ En 1844, Memoria sobre la conveniencia y objetos de un Congreso General Americano, ya aludida anteriormente, y Defensa de El Mercurio en un juicio de imprenta. En 1845, Los Americanos ligados al extranjero; Acción de Europa en América; Defensa de Justo Pastor Peña; Cuadro sinóptico del Derecho Constitucional Chileno; Veinte días en Génova. En 1846, Legislación de la Prensa en Chile; De la Magistratura y sus atribuciones en Chile; Biografía del General don Manuel Bulnes. En 1847, Alegato por parte de don Guillermo F. Huelin; Alegato presentado al Tribunal Consular en Valparaíso por parte de don Guillermo F. Huelin; La República Argentina treinta y siete años después de la Revolución de Mayo; Defensa de don Francisco de $S$. Vidal. En 1848, Manual de Ejecuciones y Quiebras; Índice alfabético del Boletín de las leyes y decretos del Gobierno de Chile; Demanda contra la casa de Le Quellec y Bordes. En 1850, Carta sobre los estudios convenientes para formar un abogado con arreglo a las necesidades de la sociedad actual en Sud América. En 1851, Estudios Políticos; El Edén; Tobías o la cárcel a la vela. En 1852, Bases y puntos de partida para la Constitución Política de la República de Argentina; Hombres públicos de Chile; Noticia biográfica de don Pedro Palazuelos. En 1853, Complicidad de la prensa en las guerras civiles de la República Argentina; Cartas sobre la Prensa y la política militante; Elementos del Derecho Público provincial. En 1854, Sistema económico y rentístico de la Confederación Argentina. Briseño registra, además, sin fecha de aparición, la que corresponde a 1846 , si o no.

No consigna su Estadística Bibliográfica, otras obras dadas a luz en Chile: Examen de la Constitución Provincial de Buenos Aires; la Integridad nacional de la República Argentina; y el Apéndice de ésta, que citan como de este período los Apuntes Biográficos del Doctor don Juan Bautista Alberdi, de Bilbao y Reynal O'Connor.

Dice Alberdi, en las páginas de En Chile, que en 1845 escribió en el Hotel Inglés de Valparaíso, su Manual del Subdelegado. Es, sin duda, el que Briseño menciona en ese mismo año con el título Manual Administrativo y Judiciario del Subdelegado en Chile, cuya paternidad impresa es «Por un abogado en nuestras cortes», la cual encubre el nombre de Alberdi. Y finalmente, en ese trabajo semianónimo se encuentra el título de un Manual del Escritor, que Briseño no anota en forma alguna y que queda atribuido al propio autor. 
Alberdi señala sobre el ethos y configuración ideológica política de la Constitución conservadora en sus «Bases y puntos de partida para la organización política de la República Argentina» lo siguiente:

«La Constitución de Chile, superior en redacción a todas las de Sud América, sensatísima y profunda en cuanto a la composición del poder ejecutivo, es incompleta y atrasada en cuanto a los medios económicos de progreso y a las grandes necesidades materiales de la América española»?

También Alberdi destaca que la Constitución conservadora de 1833 está fundada en un constituyente originario:

«Redactada por don Mariano Egaña, más que una reforma de la constitución de 1828, como dice su preámbulo, es una tradición de las constituciones de 1813 y 1823, concebidas por su padre y maestro en materia de política, don Juan Egaña, que eran una mezcla de lo mejor que tuvo el régimen colonial, y de lo mejor del régimen moderno de la primera época constitucional. Esta circunstancia que explica el mérito de la actual constitución de Chile, es también la que hace su deficiencia».

Además Alberdi observa el provincianismo de la Constitución de 1833, frente a su talante cosmopolita o europeizante, señalando:

«Los dos Egañas, hombres fueres en teología y en legislación, acreedores al respecto y agradecimiento eterno de Chile por la parte que han tenido en su organización constitucional, comprendían mal las necesidades económicas de la América del Sud; y por eso sus trabajo constitucionales no fueron concebidos de un modo adecuado para ensanchar la población de Chile por condiciones que facilitasen la adquisición de la ciudadanía. Excluyeron todo culto que no fuese el católico, sin advertir que contrariaban mortalmente la necesidad capital de Chile, que es la de su población por inmigraciones de los hombres laboriosos y excedentes que ofrece la Europa protestante y disidente. Excluyeron de los empleos administrativos y municipales y de la magistratura a los extranjeros, y privaron al país de cooperadores eficacísimos en la gestión de su vida administrativa».

Sobre las ideas económicas de la oligarquía mercantil recogidas en la Constitución conservadora Alberdi anota:

«Las ideas económicas de don Juan Egaña son dignas de mención, por haber sido el preparador o promotor principal de las instituciones que hasta hoy rigen,

9 ALBERDI, Juan Bautista, Obras Escogidas, Buenos Aires, Editorial Luz del Día, Vol. I, pp. 28-30.También es menester destacar su correspondencia en dos obras. La citada «Obras Escogidas» con las Cartas Inéditas a Juan María Gutiérrez y a Félix Frías, recopilación a cargo de J. M Mayer y E. A. Martínez, Buenos Aires, Editorial Luz de Día, 1953, y Epistolario 1855-1881 a cargo del cuidado de Bulnes, Alfonso, Santiago, Editorial Andrés Bello, 1967. 
y el apóstol de muchas convicciones y que hasta ahora son obstáculos en política comercial y económica para el progreso de Chile».

«Puesto (Chile) a los extremos de la tierra, y no siéndole ventajoso el comercio de tráfico o arriería, no tendrá guerras mercantiles, y en especial la industria y agricultura, que casi exclusivamente le conciernen, y que son las sólidas, y tal vez únicas profesiones de una república...»

«En materia de empréstitos, que serán el nervio del progreso material en América, como lo fueron de la guerra de su independencia, don Juan Egaña se expresaba de este modo comentando la constitución de 1813: "No tenemos fondos para hipotecar, ni créditos: luego no podemos formar una deuda". "Cada uno debe pagar la deuda que ha contraído por su bien. Las generaciones futuras no son de nuestra sociedad, ni podemos obligarlas". "Las naciones asiáticas no son navegantes". "La localidad de este país no permite un arrieraje y tráfico útil". "La marina comerciante excita el genio de ambición, conquista y lujo, destruye las costumbres y ocasiona celos, que finalizan en guerra". "Los industriosos chinos sin navegación viven, quietos y servidos de todo el mundo"».

Asimismo es muy ilustrativo el juicio de Alberdi sobre la cerrazón o ultramontanismo de los Egaña en particular y de la oligarquía en general al subrayar:

«En materia de tolerancia religiosa, he aquí las máximas de don Juan Egaña:

"Sin religión uniforme se formará un pueblo de comerciantes, pero no de ciudadanos".

"Yo creo que el progreso de la población no se consigue tanto con la gran libertad de admitir extranjeros, cuanto con facilitar los medios de subsistencia y comodidad a los habitantes; de suerte que sin dar grandes pasos en la población, perdemos mucho en el espíritu religioso".

"No condenemos a muerte a los hombres que no creen como nosotros; pero no formemos con ellos una familia".

"He aquí el origen alto e imponente de las aberraciones que tanto cuesta vencer a los reformadores liberales de estos días en materias económicas en la República de Chile"».

También en las «Bases» Alberdi comenta el estatuto del poder de la Constitución conservadora:

«Llamaré únicamente la atención, sin salir de mi objeto, a dos puntos esenciales que han de tenerse en vista en la constitución del Poder Ejecutivo, tanto nacional como provincial. Este es uno de los rasgos en que nuestra constitución hispano-argentina debe separarse del ejemplo de la constitución federal de los Estados Unidos ${ }^{10}$.

\footnotetext{
10 ALBERDI, Juan Bautista, op. cit., nota 8, pp. 134-138.
} 
«Bien sabido es que no hemos hecho la revolución democrática en América para restablecer ese sistema de gobierno que antes existía, ni se trata de ello absolutamente; pero si queremos que el poder ejecutivo realista, debemos poner alguna atención en el modo como se había organizado aquél para llevar a efecto su mandato».

«Los tiempos y los hombres que recibieron por misión proclamar y establecer en la América del Sud el dogma de la soberanía radical del pueblo, no podían ser adecuados para constituir la soberanía derivada y delegada del gobierno. La revolución que arrebató la soberanía y los reyes para darla a los pueblos, no ha podido conseguir después que éstos la deleguen en gobiernos patrios tan respetados como los gobiernos regios; y la América del Sud se ha visto colocada entre la anarquía y la omnipotencia de la espada por muchos años».

En cuanto a las encrucijadas en que se sitúan los países de América del Sur con la revolución de la Independencia al forjar el Estado y su arreglo institucional Alberdi señala:

«Dos sistemas se han ensayado en la extremidad meridional de la América antes española, para salir de esa posición. Buenos Aires colocó la omnipotencia del poder en las manos de un solo hombre, erigiéndole en hombre-ley, en hombre-código. Chile empleó una constitución en vez de la voluntad discrecional de un hombre; y por esa constitución dio al poder ejecutivo los medios de hacerla respetar con la eficiencia de que es capaz la dictadura misma».

«El tiempo ha demostrado que la solución de Chile es la única racional en repúblicas que poco antes fueron monarquías».

Sobre el arreglo institucional de Chile Alberdi observa nítidamente el «despotismo legal» por el que se inclina la Constitución conservadora:

"Chile ha hecho ver que entre la falta absoluta de gobierno y el gobierno dictatorial hay un gobierno regular posible; y es el de un presidente constitucional que pueda asumir las facultades de un rey en el instante que la anarquía le desobedece como presidente republicano».

«Si el orden, es decir, la vida de la constitución, exige en América esa elasticidad del poder encargado de hacer cumplir la constitución, con mayor razón la exigen las empresas que interesan al progreso material y al engrandecimiento del país. Yo no veo por qué en ciertos casos no puedan darse facultades omnímodas para vencer el atraso y la pobreza, cuando se dan para vencer el desorden, que no es más que el hijo de aquéllos».

«No: en vez de dar el despotismo a un hombre, es mejor darlo a la ley. Ya es una mejora el que la severidad sea ejercida por la constitución y no por la voluntad de un hombre. Lo peor del despotismo no es su dureza, sino su inconsecuencia, y sólo la constitución es inmutable». 
El anotado «despotismo legal» en el arreglo institucional se aquilata en una centralidad presidencial o Poder Ejecutivo omnipotente:

«Dad al poder ejecutivo todo el poder posible, pero dádselo por medio de una constitución».

«Este desarrollo del poder ejecutivo constituye la necesidad dominante del derecho constitucional de nuestros días en Sud-América. Los ensayos de monarquía, los arranques dirigidos a confiar los destinos públicos a la dictadura, son la mejor prueba de la necesidad que señalamos. Esos movimientos prueban la necesidad, sin dejar de ser equivocados y falsos en cuanto al medio de llenarla».

«Pero hemos venido a tiempos y circunstancias que reclaman un cambio en el derecho constitucional sud-americano, respecto a la manera de constituir el poder ejecutivo».

Termina Alberdi atemperando su liberalismo, cediendo a la tosca realidad histórica, y para ello justifica la centralidad presidencial:

«Las garantías individuales proclamadas con tanta gloria, conquistadas con tanta sangres, se convertirán en palabras vanas, en mentiras relumbrosas, si no se hacen efectivas por medio de las garantías públicas. La primera de éstas es el gobierno, el poder ejecutivo revestido de la fuerza capaz de hacer efectivos el orden constitucional y la paz, sin los cuales son imposible la libertad, las instituciones, la riqueza, el progreso".

«La paz es la necesidad que domina todas las necesidades públicas de la América del Sud. Ella no necesitaría sino de la paz para hacer grandes progresos».

«Pero no lo olvidéis: la paz sólo viene por el camino de la ley. La constitución es el medio más poderoso de pacificación y de orden. La dictadura es una provocación perpetua a la pelea; es un sarcasmo, un insulto sangriento a los que obedecen sin reserva. La dictadura es la anarquía constituida y convertida en institución permanente. Chile debe la paz a su constitución, y no hay paz durable en el mundo que no repose en un pacto expreso, conciliatorio de los intereses públicos y privados».

Concluye Alberdi nuevamente poniendo de ejemplo la estabilidad institucional de Chile, reivindicando el rol «demiúrgico» de los Egaña, en la forja de ese orden jurídico-político:

«La constitución ha dado el orden y la paz, no por acaso, sino porque fue ése su propósito, como lo dice su preámbulo. Lo ha dado por medio de un poder ejecutivo vigoroso, es decir, de un poderoso guardián del orden-misión esencial del poder, cuando es realmente un poder y no un nombre. Este rasgo constituye la originalidad de la constitución de Chile, que, a mi ver, es tan original a su modo como la de los Estados Unidos. Por él se ligó a su base histórica el poder en Chi- 
le, y recibió de la tradición el vigor de que disfruta. Chile supo innovar en eso con un tacto de estado, que no han conocido las otras Repúblicas. La inspiración fue debida a los Egañas, y el pensamiento remonta a 1813».

\section{CONCLUSIONES}

En el «espíritu de época» de la Constitución conservadora dominan las ideas de la colonia. Un balance realiza nuestro historiador Ricardo Donoso: «Los historiadores chilenos reconocen que la Constitución de 1833 da forma jurídica a la realidad social y que Chile constituiría desde entonces una república, basada en la influencia de la aristocracia terrateniente y de la tradición colonial, y en el ejercicio efectivo de su poder político». Tal orden fundado en el dominio de una clase mezclada (burguesa-terrateniente) permitirá dar sostén a los «reinos» de los decenios de tres presidentes: Prieto, Bulnes y Montt (Gil) ${ }^{11}$.

La revolución de la Independencia es una revolución política, mas no social, por lo que no se produce un cambio de mentalidades y cultura (Heise) lo que explica lo efímero de la experiencia federal y liberal.

Entre los «publicistas» de la época (los Egaña, Juan Francisco Meneses, entre otros) dominan las ideas del tradicionalismo del siglo XVIII español, a lo sumo del despotismo ilustrado. Luego el autocratismo pelucón se resume en la obra de los constituyentes, con formas republicanas, a las que adherían otros publicistas que provenían del liberalismo como Manuel José Gandarillas; de suerte que a la Constitución se suman pronto la Ley Electoral y la Ley de Régimen Interior, ambas de 1844 y la Ley de Imprenta de 1846 más el decreto de Portales, que resumen la restauración del espíritu colonial o "peso de la noche».

Incluso es menester anotar una cierta lejanía del doctrinarismo de Egaña, con las ideas de la Convención Constituyente. Más aún las ideas político constitucionales de Mariano Egaña eran monárquico-constitucionales, añoraba la monarquía de Carlos III, como en México Lucas Alamán y como en Perú Bartolomé Herrera, todo lo cual trasuntó en su «voto particular».

El «voto particular» de Egaña fue rechazado por la Convención Constituyente, imponiéndose las formas republicanas, en particular las ideas de Gandarillas y la sustancia tradicional colonial, en suma se impone el «ideario de Portales». El mentado «ideario de Portales» es simplemente el discurso del poder del

${ }^{11}$ DONOSO, Ricardo, Las Ideas Políticas en Chile, México, Fondo de Cultura Económica, 1946, pp. 114. También consultar a G. Gil, Federico, El Sistema Político de Chile, Santiago, Editorial Andrés Bello, 1969, pp. 54-61. 
«peso de la noche» afincado en algunas ideas simples acerca del Estado centralista, el predominio de la ley, el servicio público, la subordinación de las fuerzas armadas, antimilitarismo y el orden. Luego la vocación de Portales por la política, su desprecio por los «jurisperitos», se traduce precisamente en una visión instrumental del derecho, de lo que es elocuente una de sus cartas: «De mi sé decirle, que con ley o sin ella, esa señora que llaman que llaman Constitución hay que violarla cuando las circunstancias son extremas» (Epistolario, carta de 6 de diciembre de 1834$)^{12}$.

Luego en la visión crítica de Alberdi de la Constitución conservadora de 1833, la cuestión menor es la relativa a la autoría del texto asignada a Egaña y la cuestión de fondo es que tal Carta política aquilata, con formas republicanas las ideas de los Egaña, las ideas políticas de la clase dirigente, afincada en el pasado, y frente a la cual el liberalismo y "pipiolismo» no fueron sino epocales fenómenos del proceso histórico de formación del Estado nacional.

En cuanto a la cuestión menor relativa a la «autoría» del texto de la Constitución es muy ilustrativo el juicio del constitucionalista de entre-siglos A. Roldán:

«Es indudable que desde el principio se diseñaron dos corrientes. Una de ellas pretendía tomar como base la Constitución de 1828, haciendo las modificaciones parciales que reclamaban las nuevas circunstancias, y que se creía indispensable realizar para consolidar el orden público. Gandarillas, que había sido miembro de ministerios liberales, opinaba de esta manera. No convenía con que se prescindiera de la Constitución, temeroso de una reacción anti-liberal.

La otra corriente era encabezada por Egaña (Mariano) y tendía a dejar sin efecto en todas sus partes la Constitución, a fin de que se dictase otra completamente nueva.

Tanto Gandarillas como Egaña presentaron a la comisión proyectos de reforma, pero ninguno de estos proyectos fue aceptado. La comisión redactó otro que hasta cierto punto conciliaba las ideas de aquellos. Este proyecto es una obra impersonal, de manera que no puede ser atribuido a ninguno de los miembros determinadamente.

Egaña publicó entonces el suyo, que fue llamado «Voto particular», en el cual dio forma a todas sus opiniones. Entre estas opiniones figuraban la de constituir

12 Consultar para un breve perfil del estadista y hombre práctico Portales a Galdames, Luis, Historia de Chile. La Evolución Constitucional, Santiago, Edita Balcells \& Co., 1925, pp. 832853, sobre el mito de Portales el libro de Villalobos, Sergio, Portales, una falsificación histórica, Santiago, Editorial Universitaria, 1989 y sobre un perfil humano del «dictador civil» el trabajo del joven historiador Ossa, Juan Luis, en el libro colectivo XIX Historias del Siglo Diecinueve Chileno, Santiago, Editorial Vergara, 3. ${ }^{a}$ ed., 2007. 
una parte del Senado con altos funcionarios de la administración pública y la de dar al Presidente la facultad de disolver la Cámara de Diputados.

Por su parte, Gandarillas rehusó suscribir el proyecto de la comisión, con el objeto de reservarse, probablemente, toda su libertad en los debates que debían tener lugar más tarde.

El proyecto presentado por la comisión fue aprobado con diversas modificaciones, propuestas principalmente por Egaña y vino a ser Constitución de $1833 »^{13}$.

También es muy digno de anotar la opinión recogida por un agudo historiador constitucional como Luis Galdames, quien destaca el influjo de Egaña y del «voto particular»:

" No habría estado, pues, Egaña en ningún momento conforme con sus colegas de trabajo i como sus indicaciones no fueron atendidas sino excepcionalmente, quiso darles una redacción ordenada hasta hacer de ellas un estatuto completo, en contraposición al que se decía obra de todos»..." (el fin de Egaña) ...organizar el Estado bajo apariencias republicanas, pero a base de instituciones monárquicas, en provecho exclusivo de la oligarquía colonial, que tendría en su presidente un soberano vitalicio, elejido i controlado por ella misma».

El mismo Galdames sobre el efectivo influjo constituyente de Egaña en la Constitución finalmente aprobada, agrega:

«Pretender disimilar o diluir el pensamiento de Egaña, patente en sus escritos i actitudes de estadista, porque en su espíritu monárquico no prevaleció, lejos de exaltarlo históricamente, lo empequeñece i desfigura... La Comisión de reforma hubo de tomar mui en cuenta el voto de Egaña, aún cuando Gandarillas lo combatiera hasta el ridículo en El Araucano... Ni el origen, en el sentido, ni las modalidades propias de los preceptos fundamentales de la Constitución de 1833, serían explicables si se prescindiera del conocimiento i estudio de aquel voto» ${ }^{14}$.

Además podemos observar en Alberdi un liberalismo atemperado por la tosca materia: la historia, y de allí su descreimiento en torno a modelos de organización política, su moderado federalismo y apasionada defensa de la centralidad presidencial. También observamos en su correspondencia un nexo de gratitud y admiración por Chile: «...la mejor república de la América», y la preocupación constante por eventuales conflictos entre las repúblicas de ambos lados de los

13 ROLDÁN ALCIBÍADES, Elementos de Derecho Constitucional de Chile, Valparaíso, Imprenta-Litografía Barcelona, 2. ${ }^{a}$ ed., 1917, pp. 86-87.

${ }^{14}$ GALDAMES, Luis, op. cit., nota 11, pp. 884-885, pp. 895 y pp. 898-899. 
Andes o la incomprendida defensa del Paraguay (con ello de una idea de unidad sudamericana, de base aduanera y comercial) frente a la guerra de la Triple Alianza.

Al mismo tiempo Alberdi es un publicista sin igual en su tiempo histórico, con una producción en cantidad y calidad difícil de comparar, con una agudeza histórica y un pragmatismo que lo aproxima a la política y lo transforma en el "padre de la Constitución de 1853». Las comentadas «Bases...» y su lectura positiva-crítica de la Constitución conservadora de 1833 son un botón de muestra de esta producción.

Con la Constitución conservadora o pelucona, se impone el «peso de la noche» con su sustancia mercantil, agraria, clerical o ultramontana, y un fuerte autoritarismo presidencial, con formas republicanas, distantes del monarquismo de Mariano Egaña. Por ello valorando la organización republicana de Chile, de fondo monárquico y forma republicana, Alberdi crítica los factores de atraso económico, racial, cultural y religioso del país, y concluye en sus «Bases...»: «Chile ha escapado del desorden, pero no del atraso y de la soledad» (p. 180).

Luego, la estabilidad o "legitimidad» de este orden del Estado nacional consolidado, es una legitimidad histórica o social tradicional en el enfoque weberiano. La Constitución conservadora responde a un concepto "histórico tradicional», opuesta al concepto "racional normativo» a que adscribe la Constitución liberal de 1828, expresión del conservatismo frente al liberalismo, de la fuerza conformadora de la vida socio estatal que descansa en el pasado; y en algunos casos expresión de un liberalismo templado que concilia razón y pasado histórico, opuesto al absolutismo monárquico y a la democracia como lo fue el "liberalismo doctrinario» que tuvo sus ecos en nuestra América ${ }^{15}$.

En su raíz histórica: el «peso de la noche» estriba la clave explicativa de la duración de la Constitución y su régimen casi sin fisuras hasta 1861 (Heise), mediando la "cuestión del sacristán» (1856), que quiebra la unidad de las clases dirigentes, $\mathrm{y}$ también explica en parte la mutación del régimen oligárquico durante el siglo XIX ${ }^{16}$.

15 Consultar el libro clásico de García Pelayo, Manuel, Derecho Constitucional Comparado, Madrid, Alianza Editorial, 1984, pp. 41-47.

16 Sobre la «cuestión del sacristán» consultar el trabajo del joven historiador Moscoso, Pablo en obra colectiva XIX Historias del siglo Diecinueve Chileno, Santiago, Editorial Vergara, 3. ${ }^{\mathrm{a}}$ ed., 2007. 
Title

CONSERVATIVE CONSTITUTION OF CHILE OF 1833 AND THE CRITICAL VISION OF ALBERDI.

\section{Resumen}

El presente trabajo reflexiona acerca de la lectura positiva y crítica del jurista argentino Juan Bautista Alberdi relativa a la Constitución conservadora de 1833, y en especial el rol de Mariano Egaña en la génesis de la Carta Fundamental.

\section{Abstract}

The present work reflects about the lecture positive and critical of lawyer argentine Juan Bautista Alberdi relative to an conservative Constitution of 1833, and specially the role of Mariano Egaña in the genesis of the Fundamental Law.

\section{Palabras claves}

Constitución, constitucionalismo, liberalismo moderado, historicismo, autoritarismo presidencial.

\section{Key words}

Constitution, constitutionalism, liberalism moderate, historicism, authoritarism presidential. 